\title{
Two Cases of 45,X/47,Xxx Turner Mosaicism With Different Growth Patterns Possibly Caused By Different Growth Hormone Therapies
}

\author{
Chihiro Nozaki and Tatsuhiko Urakami* \\ Department of Pediatrics, Japan \\ *Corresponding author: Tatsuhiko Urakami, Department of Pediatrics, Japan
}

\section{ARTICLE INFO}

Received: 㓞January 30, 2019

Published: 慧 February 07, 2019

Citation: Chihiro Nozaki, Tatsuhiko Urakami. Two Cases of 45,X/47,Xxx Turner Mosaicism With Different Growth Patterns Possibly Caused By Different Growth Hormone Therapies. Biomed J Sci \& Tech Res 14(2)-2019. BJSTR. MS.ID.002515.

\section{ABSTRACT}

We reported two Japanese girls with 45,X/47,XXX Turner mosaicism, who showed different growth patterns possible caused by different growth hormone $(\mathrm{GH})$ therapies. The first case was diagnosed with 45,X/47,XXX mosaicism at the age of 7 years, and a high-dose GH hormone therapy $(0.35 \mathrm{mg} / \mathrm{kg} /$ week $)$ started from the diagnosis. While, the second case was initially treated with a low-dose GH therapy $(0.175 \mathrm{mg} / \mathrm{kg} /$ week $)$ on the basis of diagnosis of GH deficiency from 7 years of age. However, the incidental chromosomal test identified her as 45,X/47,XXX mosaicism, and GH therapy was changed to high-dose replacement at the age of 12 years. We compared the growth patterns between the two cases. Case 1 obtained significant increased growth (height SDS from -3.1SD to -2.4SD), while, case 2 could not attain the sufficient growth (height SDS from 2.5SD to -2.4SD). They entered puberty spontaneously and achieved menarche without the use of estradiol. These findings suggest that mild clinical manifestations observed in $45, \mathrm{X} / 47, \mathrm{XXX}$ mosaicism might guide to undiagnose Turner syndrome and delay of start of an adequate-dose GH therapy.

Earlier diagnosis and an appropriate GH therapy can improve the clinical course and prognosis. Turner syndrome is defined as partial or complete loss of one of the $\mathrm{X}$ chromosomes, affecting 1:2,000 to 2,500 live female births [1]. The syndrome is highly variable can differ dramatically among the cases. Affected females potentially develop a wide variety of clinical features, affecting various organ systems. Common features include short stature, ovarian failure and phenotypic abnormalities. Turner syndrome may be diagnosed shortly after birth or during early childhood, while mild cases can remain undiagnosed until later in life and even during adulthood. High-dose recombinant growth hormone (GH) therapy $(0.35 \mathrm{mg} / \mathrm{kg} /$ week) for Turner syndrome was permitted for use in Japan in 2000, and it can help to achieve greater height than low-dose GH therapy $(0.175 \mathrm{mg} / \mathrm{kg} /$ week $)$ used for growth hormone deficiency $[2,3]$. Most cases with Turner syndrome need sex hormone replacement therapy in order to undergo pubertal development and begin their menstrual periods following the GH therapy. On the other hand, few individuals with Tuner syndrome show minimal symptoms, adequate growth and spontaneous, progressive puberty.

$45, \mathrm{X} / 47, \mathrm{XXX}$ Turner mosaicism, which is a rare type of mosaicism, is recognized to have the improved prognosis for growth and ovarian function [4-9] have reported that females with 45,X/47,XXX mosaicism are more mildly affected clinically. They have near normal ovarian function with spontaneous puberty. They also show mild growth retardation, and some cases do not require GH therapy. In the present study, we reported two Japanese girls with $45, X / 47, X X X$ Turner mosaicism, who showed different growth patterns possible caused by different GH therapies. The first case was diagnosed with 45,X/47,XXX mosaicism at the age of 7 years, and a high-dose GH hormone therapy started from the diagnosis. While, the second case was initially treated with a low-dose GH therapy as growth hormone deficiency from 7 years of age. However, the incidental chromosomal test identified 45,X/47,XXX mosaicism, and GH therapy was changed to high-dose replacement at the age of 12 years. We compared the growth development between the two cases. 


\section{Case Report}

\section{Case 1}

A 7-year old Japanese girl was referred to our department due to short stature with a height SDS of -3.1SD. She had minimal physical features of Turner syndrome, mild cubitus valgus and short neck, but without webbed appearance. She had no organic abnormalities. Laboratory data showed normal serum levels of IGF-1 (101ng/ $\mathrm{mL})$, LH $(2.0 \mathrm{mIU} / \mathrm{mL})$, FSH $(3.9 \mathrm{mIU} / \mathrm{mL})$ and estradiol $(<10 \mathrm{pg} /$ $\mathrm{mL}$ ), which were coincident with her age and pubertal stage Tanner stage 1 . The bone age was 7 years old. She showed normal response to $\mathrm{GH}$ provocation tests. We performed a chromosomal analysis suspecting Turner syndrome, and 45,X/47,XXX mosaicism was identified. We started a high-dose GH therapy $(0.35 \mathrm{mg} / \mathrm{kg} /$ week $)$, and the satisfied growth response was achieved (Figures 1 \& 2). The height SDS was improved from -3.1 SDS to -2.4 SDS, and from -0.6 SD to +1.8SD for Japanese girls with Turner syndrome [10]. There was spontaneous and progressive puberty and she achieved menarche at the age of 12 years without the use of estrogen.

\section{Case 1}

$(\mathrm{cm})$

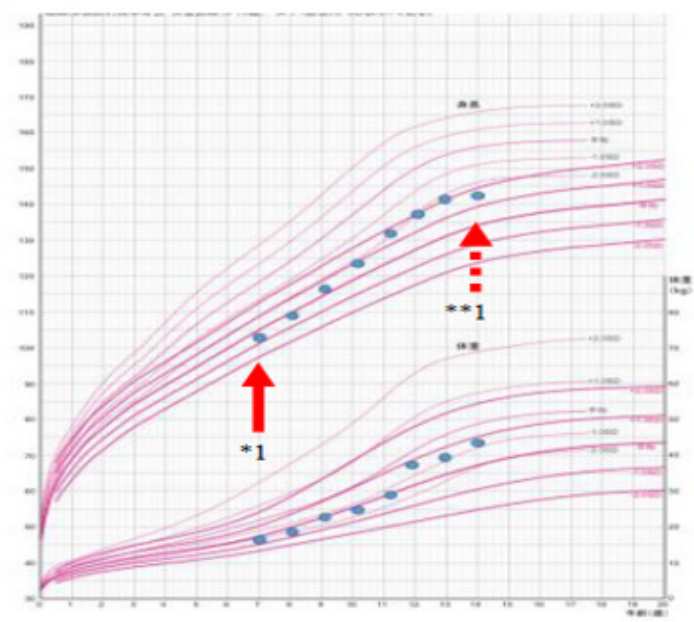

\section{Case 2}

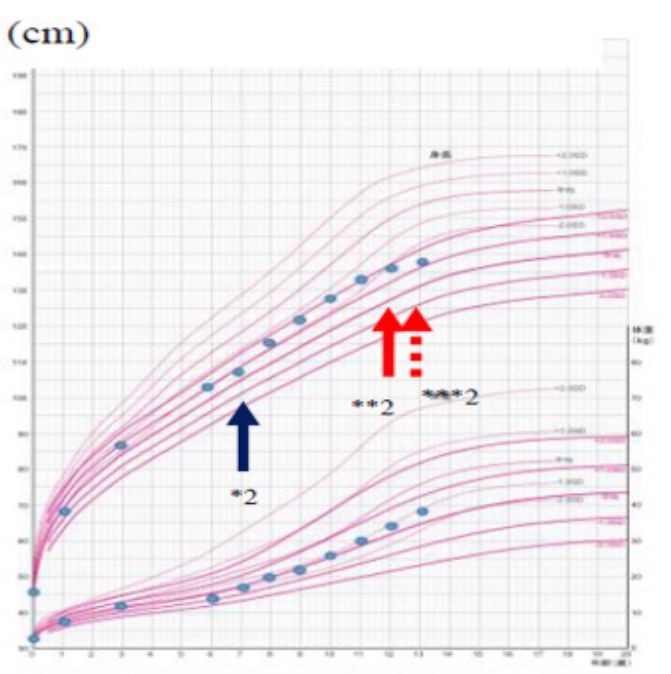

Note: *1: start of a high-dose GH therapy, ${ }^{* *} 1$ : finish of a high-dose GH therapy. ${ }^{*} 2$ : start of a low-dose GH therapy, **2: change to a high-dose GH therapy. ${ }^{* *} 2$ : finish of a high-dose GH therapy.

Figure 1: Growth charts in Case 1 and Case 2.

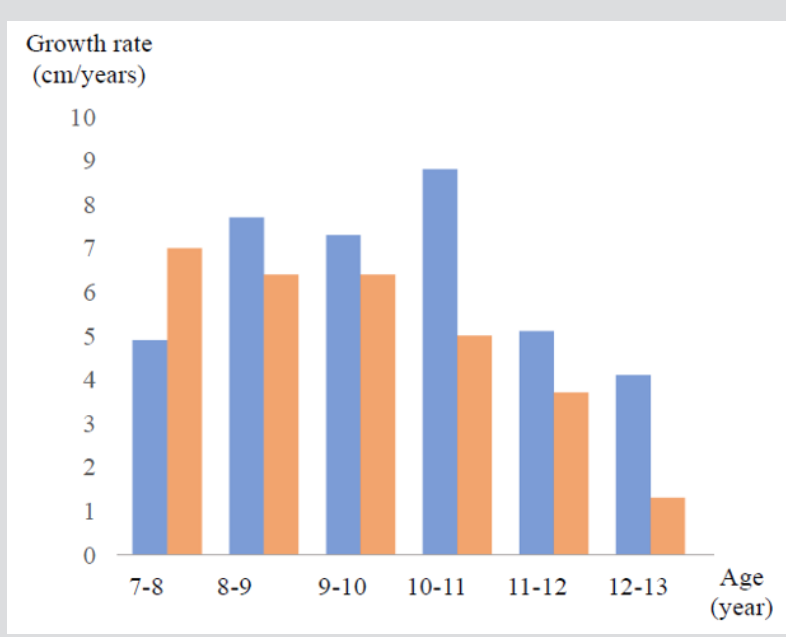

Figure 2: Comparison of the growth rates between Case1 and Case 2.

Note: Blue bards indicate the growth rates in Case 1, and red bars indicate that in Case 2. 


\section{Case 2}

Another case was also a 7-year old Japanese girl with short stature of height SDS of -2.5SD. She was initially not recognized as Turner syndrome by a pediatrician at the local clinic, because the physical features were minimum. She had no organic abnormalities. According to the results of GH provocation tests, she was diagnosed with GH deficiency, and a low-dose GH therapy $(0.175 \mathrm{mg} / \mathrm{kg} /$ week) was started. At first, the GH therapy seemed effective for growth, but her growth rate gradually decreased. Eventually, there was no significant improvement in the height SDS (from - 2.5 SDS to -2.4 SDS, and from +0.9 SD to +1.8SD for Japanese girls with Turner syndrome) (Figures $1 \& 2$ ). She entered puberty spontaneously and achieved menarche at the age of 11 years and 6 months without the use of estradiol. Thereafter, she referred to our department at the age of 12 years. We found some distinctive physical features, cubitus valgus, shield-like chest, low hairline and short neck, and performed a chromosomal analysis, which identified 45,X/47,XXX mosaicism. At the age of 12 years, serum levels of IGF-1 (405ng/ $\mathrm{mL}), \mathrm{LH}(6.9 \mathrm{mIU} / \mathrm{mL}), \mathrm{FSH}(6.5 \mathrm{mIU} / \mathrm{mL})$ and estradiol $(109.5 \mathrm{pg} /$ $\mathrm{mL}$ ) were equivalent to her age and pubertal stage Tanner stage 4. The bone age was 12 years old. We changed to a high-dose GH therapy after confirmation of the Turner karyotype, but her growth rate was not accelerated.

\section{Discussion}

Various studies have indicated that Turner syndrome caused by $45, \mathrm{X} / 47, \mathrm{XXX}$ mosaicism are more mildly affected clinically, particularly growth and ovarian function. Blair et al. [9] reported that although the median height SDS of 7 girls with 45,X/47,XXX mosaicism was not significantly different from those with the commoner karyotypes, 3 girls did not require GH treatment, and the height SDSs in 6 out of 7 girls were within normal range for normal girls at review. These findings suggest that the karyotype of 45,X/47,XXX might be more likely manifest growth impairment than the commoner karyotypes. On the other hand, a high-dose GH therapy started from early childhood can offer greater improvement of final height in Turner syndrome. Takano et al. [2,3,11] reported that girls with Turner syndrome received a high-dose GH therapy more greatly increased the growth rates during the initial 4 years compared with those with a low-dose GH therapy. The mean final height treated for more than 6 years was $142.2 \pm 6.5 \mathrm{~cm}$ with a lowdose $\mathrm{GH}$ and $144.3 \pm 3.9 \mathrm{~cm}$ with a high-dose $\mathrm{GH}$, although there was no statistical difference between the two dose regimens. Besides, Marco et al. [12,13] have indicated that predictors of good response to GH therapy can be the time on growth hormone therapy until starting estrogen replacement therapy as well as the initial GH dosage.

Turner syndrome with $45, \mathrm{X} / 47, \mathrm{XXX}$ mosaicism is known to have milder growth failure, while a high-dose GH therapy from early childhood can achieve near normal final height. In the present study, case 1 obtained significant increased growth (height SDS from $-3.1 \mathrm{SD}$ to $-2.4 \mathrm{SD}$ ) treated with a high-dose GH from 7 years of age. While, case 2 could not attain the sufficient growth (height SDS from $-2.5 \mathrm{SD}$ to $-2.4 \mathrm{SD}$ ), because she was initially treated with a low-dose GH from 7 years of age due to misdiagnosis as GH deficiency, and the therapy changed to a high-dose GH after confirmation of Turner syndrome at the age of 12 years. Mild clinical features observed in $45, \mathrm{X} / 47$, XXX mosaicism might guide to undiagnosis of Turner syndrome and delay of start of an adequate-dose GH therapy, which can cause failure to attain the satisfied final height. 45,X/47,XXX mosaicism enables to enter puberty spontaneously, and some cases do not have to treat with estrogen to progress puberty. On the other hand, girls with this karyotype can develop bone maturation and achieve epiphysial closure earlier than those with the commoner karyotypes. In the present study, both girls achieved menarche before 12 years of age, which could influence on their final height, particularly in case 2, whose final height was similar to the mean final height in untreated girls with Turner syndrome with the commoner karyotypes [11]. Earlier spontaneous puberty can inhibit the improved growth characterized in $45, \mathrm{X} / 47$, XXX Turner mosaicism. In conclusion, girls with 45,X/47,XXX Turner mosaicism are more mildly affected clinically with less impaired growth and less ovarian failure. However, they are more likely to remain undiagnosed until later in life, which can cause inhibit improved final height and satisfied quality of life. Earlier diagnosis and an appropriate GH therapy can improve their growth patterns and prognosis.

\section{Disclosure}

T.U. received honoraria from Novo Nordisk, Sanofi and Japan Chemical Research as a speaker and for attendance at advisory boards. C.N. declares no conflict of interest.

\section{References}

1. Nielson J, Wohlet TM (1991) Chromosome abnormalities found among 34910 newborn children: results from a 13-year incidence study in Arhus, Denmark. Hum Genet 87(1): 81-83.

2. Ranke MB, Lindberg A (2011) Observed and predicted total pubertal growth during treatment with growth hormone in adolescents with idiopathic growth hormone deficiency, Turner syndrome, short stature, born small for gestational age and idiopathic short stature: KIGS analysis and review. Horm Res Paeditr 75(6): 423-432.

3. Tai S, Tanaka T, Hasegawa T, Ozono K, Tanaka H, et al. (2013) An observation study of the effectiveness of growth hormone (HumatropeoR) treatment in Japanese children with growth hormone deficiency and Turner syndrome. Endocr J 60: 57-64.

4. Massa G, Vanderschueren Lodeweyckx M, Malvaux P (1990) Liner growth in patients with Turner's syndrome and parental height. Eur J Pediatr 149: 246-250.

5. Cohen A, Kauli R, Lavagetto A, Roitmano Y, Pertzelan A, et al. (1995) Final height of girls with Turner's syndrome: correlation with karyotype and parental height. Acta Paediatr 84(5): 550-554.

6. Koerberl DD, Mc Gillvray B, Sybert VP (1996) Prenatal diagnosis of 45, X/46, XX mosaicism and 45, X: implications for postnatal outcome. Am J Hum Genet 57(3): 661-666. 
7. Mazzanti L, Cacciari E, Bergamaschi R, Tassinari D, Margnani C, et al. (1997) Pelvic ultrasound in patients with Turner's syndrome: agerelated findings in different karyotypes. J Pediatr 131(1): 135-140.

8. Pasaquino AM, Passeri F, Pucarelli I, Segni M, Municchi G (1997) Spontaneous pubertal development in Turner's syndrome. J Clin Endocrinol Metab 82(6): 1810-1813.

9. Blaire J, Tolmie J, Hollman AS, Donaldson MDC (2001) Phenotype, ovarian function, and growth in patients with 45,X/47,XXX Turner mosaicism: implications for prenatal counseling and estrogen therapy at puberty. J Pediatr 139(5): 724-728.

10. Isojima T, Yokota S, Ito J, Horikawa R, Tanaka T (2009) New reference growth charts for Japanese girls with Turner syndrome. Pediatr Int 51(5): 709-714.

\section{ISSN: 2574-1241}

DOI: 10.26717.BJSTR.2019.14.002515

Tatsuhiko Urakami.Biomed J Sci \& Tech Res

(c) (i) This work is licensed under Creative

Submission Link: https://biomedres.us/submit-manuscript.php
11. Takano K, Ogawa M, Tanaka T, Tachibana K, Fujita K, et al. (1997) Clinical trials of GH treatment in patients with Turner's syndrome in Japan consideration of final height. The Committee for the Treatment of Turner's syndrome. Eur J Endocrinol 137(2): 138-145.

12. Marco SBS, Muňoz AA, Lozano MF, Aizpún JIL, Otero JMG (2014) Human growth hormone and Turner syndrome. Ann Pediatr 86(2): 59-106.

13. Isojima T, Kato N, Ito Y, Kanzaki S, Murata M (2016) Growth standard charts for children with mean and standard deviation (SD) values based on the year 2000 national survey. Clin Pediatr Endocrinol 25: 71-76.

$\begin{array}{ll}\text { BIOMEDICAL } & \text { Assets of Publishing with us } \\ \text { RESEARCHES } & \text { - Global archiving of articles } \\ & \text { - Immediate, unrestricted online access } \\ & \text { - Rigorous Peer Review Process } \\ \end{array}$

